\title{
Mapping the main Leishmania phlebotomine vector in the endemic focus of the Mt. Vesuvius in southern Italy
}

\author{
Erika Rossi ${ }^{1}$, Laura Rinaldi², Vincenzo Musella², Vincenzo Veneziano², Sabrina Carbone ${ }^{2}$, \\ Luigi Gradoni ${ }^{1}$, Giuseppe Cringoli ${ }^{2}$, Michele Maroli ${ }^{1}$ \\ ${ }^{1}$ Dipartimento MIPI, Istituto Superiore di Sanità, Rome, Italy; ${ }^{2}$ Dipartimento di Patologia e Sanità \\ Animale, Università degli Studi di Napoli "Federico II”, Naples, Italy
}

\begin{abstract}
Geographical information systems and remote sensing were used to analyze the distribution of the Leishmania infantum-Phlebotomus perniciosus parasite-vector system in relation to environmental features of two opposite sides (coastal and Apennine) of Mt. Vesuvius, an area of intense transmission of human and canine leishmaniasis in southern Italy. Weekly phlebotomine collections were carried out during two consecutive warm seasons (20042005 ) in 24 and 25 sites of the coastal and Apennine sides, respectively. Sandflies were caught using over one-thousand and seven hundred $20 \times 20 \mathrm{~cm}$-sticky traps placed in different environments. A total of 873 sandflies were collected, of which $284(32.5 \%)$ were identified as P. perniciosus. The cumulative density (number of specimens $/ \mathrm{m}^{2}$ of sticky trap/two nights) of this vector species was 3.9. P. perniciosus was significantly more abundant in the coastal side (5.8) as compared to the Apennine side (1.4). The main environmental differences between the two sides were the aspect (south-west for the coastal and north-east for the Apennine side) and land use. The predominance of green vegetated environments (forest, semi-natural and agricultural areas) in the coastal side, in contrast with the predominance of artificial surfaces (namely urban environment) in the Apennine side, could be responsible for the different P. perniciosus densities between the two surveyed areas.
\end{abstract}

Keywords: Phlebotomus perniciosus, sandflies, geographical information systems, leishmaniasis, Mt. Vesuvius, Italy.

\section{Introduction}

In the Mediterranean regions, the proven vectors of human and animal leishmaniasis due to Leishmania infantum are phlebotomine sandflies belonging to the subgenus Phlebotomus (Larroussius) (Diptera, Psychodidae). In Italy, P. perniciosus is regarded as the most efficient vector of human (VL) and canine (CanL) visceral leishmaniasis (Bettini et al., 1986; Maroli et al., 1988, 1994a; Bongiorno et al., 2003). Several entomological investigations have shown that this species can

Corresponding author:

Michele Maroli

Vector-borne Diseases and International Health Dipartimento MIPI, Istituto Superiore di Sanità Viale Regina Elena, 299 - 00161 Rome, Italy Tel. +39 06 49902302; Fax +3906 49903561

E-mail: michele.maroli@iss.it colonise rural, peri-urban and urban areas (Corradetti, 1962; Biocca et al., 1977; Maroli and Bettini, 1977; Bettini et al., 1991; Maroli et al., 1994b; Maroli and Khoury, 1998). Resting adults are found during daylight in both domestic and sylvatic sites, including houses and animal shelters, wall crevices, tree holes and animal burrows (Maroli et al., 1994b; Ascione et al., 1996; Maroli and Khoury, 1998).

The past 15-20 years have seen an ever increasing reliance on cartographic representation of infectious diseases, particularly parasitic infections and their vectors (Bergquist, 2006). Geographical information systems (GIS) and remote sensing (RS) technologies have become essential tools for disease mapping, ecological analyses, predicting parasite occurrence/seasonality and surveillance for various parasitic diseases (Cringoli et al., 2005; Rinaldi et al., 2006) and in 
particular arthropod-borne diseases.

With respect to phlebotomine sandflies, GIS models have been developed for P. papatasi, a vector of L. major and sandfly fever in southwest Asia (Cross et al., 1996), and the L. donovani vectors P. orientalis and P. martini in East Africa (Thomson et al., 1999; Gebre-Michael et al., 2004). More recently, GIS and RS have been used to characterize the landscape epidemiology of American VL (caused by L. infantum = syn. L. chagasi, and transmitted by the New World sandfly Lutzomyia longipalpis) in order to identify and map high risk areas and endemic zones in Bahia state in north Brazil (Bavia et al., 2005). Also, two predictive models have been developed within GIS using genetic algorithm rule-set prediction and the growing degree day-water budget concept to predict the distribution and potential risk of the disease in this Brazilian state (Nieto et al., 2006).

Following a systematic review of the literature, evidence-based GIS maps of CanL in Europe (Trotz-Williams and Trees, 2003) and Italy (Cringoli and Pietrobelli, 2006) have been drawn by a thorough analysis of recorded distribution, prevalence and incidence. A health information system has been recently proposed as a tool for the epidemiological surveillance of leishmaniasis in the city of Messina, southern Italy (Brianti et al., 2006).

The present paper describes an entomological survey conducted along two sides of the Mt. Vesuvius area of southern Italy, an area of intense transmission of VL and CanL (Gramiccia et al., 1992; Gradoni et al., 1993, 1996; Maroli et al., 2001; Baldi et al., 2004; di Martino et al., 2004; Rinaldi et al., 2005) with the sandfly P. perniciosus acting as vector (Maroli et al., 1994a; Ascione et al., 1996). GIS was used for both the design of the study and the analysis of results in order to map the distribution of $P$. perniciosus along two opposite sides (coastal and Apennine side) of the Mt. Vesuvius, and to relate its distribution to environmental features.

\section{Materials and methods}

\section{Study area}

The study was conducted in the territory of Mt. Vesuvius, a 1,281 $\mathrm{m}$ high volcano facing the eastern shore of the Bay of Naples in southern Italy. Mt. Vesuvius is a strato-volcano densely populated on its slopes. It is located in a tectonic graben formed in the Plio-Pleistocene, and it is presently in a quiescent state (Auger et al., 2001).

GIS was used in order to plan the phlebotomine sampling procedures in two sides of the volcano having similar surface areas, using the municipal boundaries as limits, and to choose a similar number of sandfly collection sites at representative elevations in the two territories. The coastal side $\left(64.1 \mathrm{~km}^{2}\right.$, facing southwest towards the Tyrrhenian Sea) includes five contiguous municipalities (San Sebastiano al Vesuvio, Ercolano, Torre del Greco, Trecase and Boscotrecase), while the Apennine side $\left(64.2 \mathrm{~km}^{2}\right.$, facing northeast towards the inland countryside) includes three contiguous municipalities (Somma Vesuviana, Ottaviano and

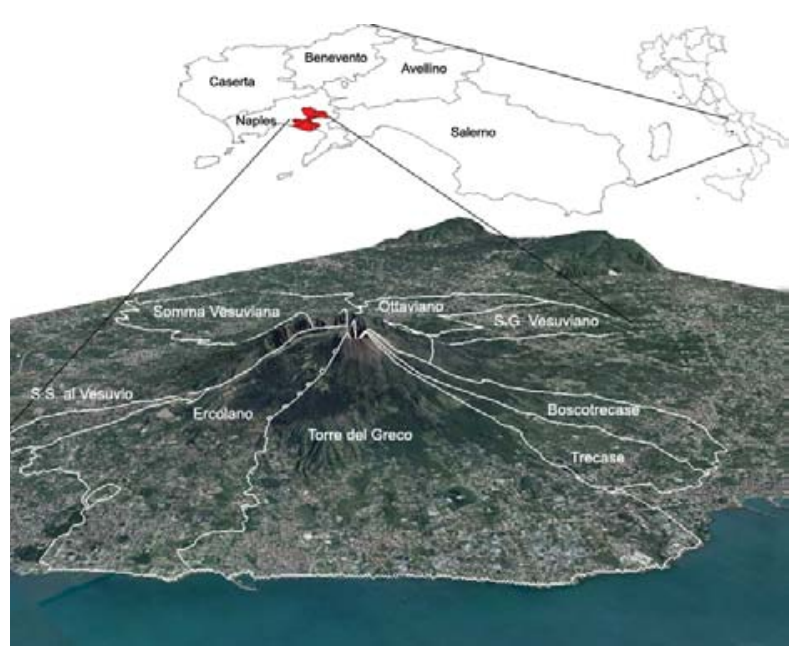

Fig. 1. The study area. Aerial photographs were overlaid on a digital elevation model for the coastal and the Apennine sides of the Mt. Vesuvius (municipality boundaries are shown in white). 
San Giuseppe Vesuviano) (Fig. 1). There are no lakes or rivers in the study area. The climate is temperate.

\section{Establishment of a GIS}

A GIS for the study area was constructed, by utilizing the following data layers: digital aerial photographs, administrative boundaries, elevation, slope, aspect, and land use.

Digital aerial photographs (at $1 \mathrm{~m}$ resolution) and administrative boundaries were obtained from the Cartographic Office of the Campania region.

Data on elevation, slope and aspect of the study area were obtained from a digital elevation model (DEM) of $40 \mathrm{~m}$ spatial resolution from the Cartographic Office of the Campania region. Overlaying DEM and digital aerial photographs, tridimensional maps of elevation, slope and aspect were obtained (Figs. 2 a,b,c). Aspect was divided into the following eight classes: north $\left(337.5-360^{\circ}\right.$ and $\left.0-22.5^{\circ}\right)$, north-east $\left(22.5-67.5^{\circ}\right)$, east $\left(67.5-112.5^{\circ}\right)$, south-east $\left(112.5-157.5^{\circ}\right)$, south $\left(157.5-202.5^{\circ}\right)$, south-west $\left(202.5-247.5^{\circ}\right)$, west $\left(247.5-292.5^{\circ}\right)$, and north-west $\left(292.5-337.5^{\circ}\right)$. Slope was divided into the following four classes: flat $\left(0^{\circ}\right)$, low $\left(1-15^{\circ}\right)$, medium $\left(16-30^{\circ}\right)$ and high $\left(31-54^{\circ}\right)$.

Land use of the study area was obtained using the "Map of Agricultural Use of Land in Campania" at a 1:50,000 scale edited in 2004 by SESIRCA (Testing, Information, Research and Consulting in Agriculture - Campania Region), supported by the Italian Association for Remotely Sensed Data in Agriculture (ITA) by interpretation of aerial photos (1998-99) and LANDSAT images (May 2001, July 2001, April 2002). It describes land use according to a nomenclature of 38 classes (level 3). These classes were grouped in order to obtain five classes (level 1) corresponding to the main categories of the land cover/land use (built-up/urban areas, agricultural areas, forest and semi-natural areas, wetlands, and water surfaces; Fig. 2d).
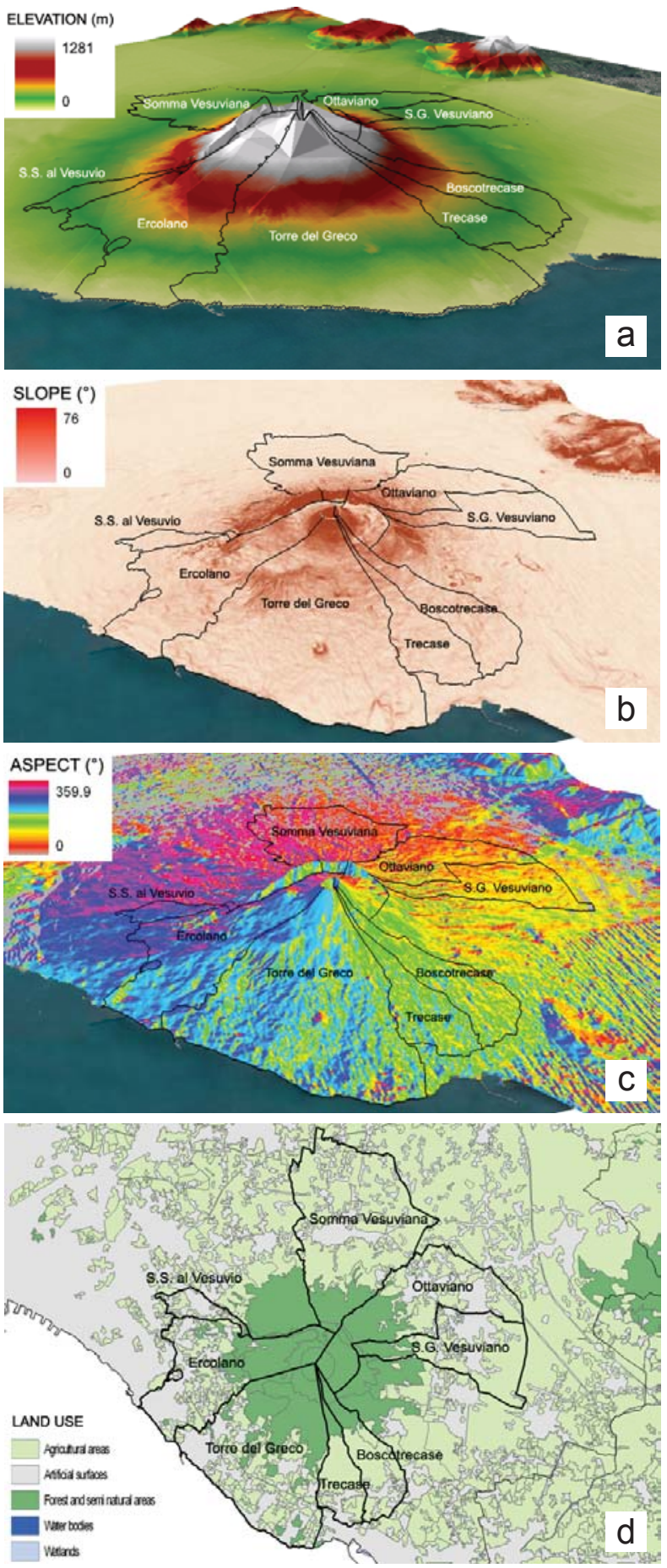

Fig. 2. Data layers used for ecological analysis: a) elevation, b) slope, c) aspect and d) land use class. 
Data on the above environmental variables were extracted for each of the geo-referenced sandfly collection sites.

All GIS databases were developed using Arc-GIS 9.1 GIS (ESRI, Redlands, CA, USA).

\section{Sandfly collection}

Weekly sandfly collections were carried out during a 4-month period (June-September) for two consecutive years (2004-2005). Using the transect sampling approach (Rinaldi et al., 2006), 49 sites were chosen, 24 in the coastal and 25 in the Apennine side of Mt. Vesuvius. Briefly, in each side, the sampling sites were distributed along transects previously selected on the aerial photos of the study area in order to represent ecological type and elevation.

A handheld geographic positioning system (GPS GARMIN 12XL, Garmin International Inc. Olathe, KS, USA) was used to identify the geographical location of the sandfly collection sites with an accuracy of $<40 \mathrm{~m}$ (Fig. 3).

Sandfly specimens were collected by using paper traps $(20 \times 20 \mathrm{~cm})$ soaked in castor oil (sticky traps) (Rioux et al., 1967; Croset et al., 1978) and left in situ for two consecutive nights. Castor oil does not have any attractive or repulsive property; therefore this method is commonly used to survey species from both domestic and wild environments. After capture, the sandflies were removed from sticky traps by means of a fine brush soaked in alcohol and stored in alcohol (95\%) pending identification. All specimens were identified to the species level by their morphological characteri- stics, according to Theodor (1958) and Léger et al. (1983).

\section{Statistical analyses}

Pearson chi-square and Fisher's exact tests were used in order to test differences among proportions.

The non-parametric Mann-Whitney U test was used in order to test differences among average measures. All statistical analyses were performed using SPSS 13.0 software for Windows.

\section{Results}

A total of 1,788 sticky traps were employed. Phlebotomine resting sites monitored included wall crevices (869 traps) and domestic places (919 traps).

About $48 \%$ of the traps (859) were placed in rural areas and the remaining (929) in environments with major human habitation, namely in urban (473) and peri-urban areas (456). The number of traps placed at each collection site ranged from 6 to 125 . A total of 873 sandflies were collected during the two-year survey, of which $284(32.5 \%$; 95\% confidence interval-CI $=29.4-35.8 \%$ ) were identified as P. perniciosus. Other Phlebotomus species were P. papatasi $(0.7 \%)$ and $P$. mascittii $(0.1 \%)$. The majority of phlebotomine specimens were found to be Sergentomyia minuta $(66.7 \%)$, a species that has no role in leishmaniasis transmission. Table 1 summarises the total number of sandflies collected and $P$. perniciosus specimens identified on the two sides of Mt. Vesuvius. Out of 49 collection sites, 27

Table 1. Sandflies collected and P. perniciosus specimens identified on the coastal and Apennine sides of Mt. Vesuvius.

\begin{tabular}{|c|c|c|c|c|c|c|c|}
\hline \multirow[t]{2}{*}{ Area } & \multirow{2}{*}{$\begin{array}{l}\text { Sandflies } \\
\text { collected }\end{array}$} & \multicolumn{5}{|c|}{ Phlebotomus perniciosus } & \multirow[t]{2}{*}{$\mathrm{P}^{\mathrm{b}}$} \\
\hline & & $\begin{array}{l}\text { No. of specimens } \\
\text { collected }\end{array}$ & $\%$ & $95 \% \mathrm{CI}$ & Density $^{\mathrm{a}}$ & $95 \% \mathrm{CI}$ & \\
\hline Coastal side & 509 & 241 & 47.3 & $42.9-51.8$ & 5.8 & $2.7-12.2$ & \\
\hline Apennine side & 364 & 43 & 11.8 & $8.8-15.7$ & 1.4 & $0.2-3.0$ & 0.043 \\
\hline Total & 873 & 284 & 32.5 & $29.4-35.8$ & 3.9 & $2.0-7.4$ & \\
\hline
\end{tabular}

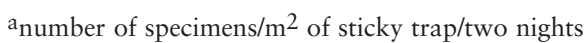

bMann-Whitney U test 


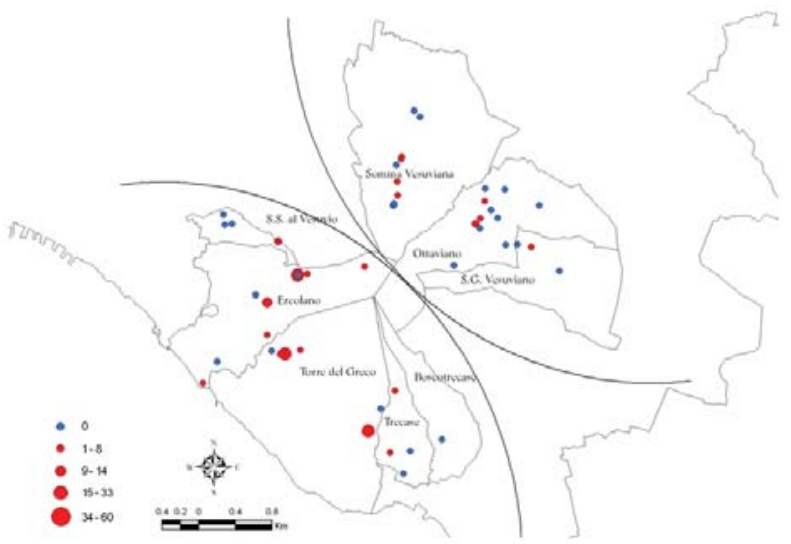

Fig. 3. Map with proportioned circles showing P. perniciosus density (mean $/ 20 \mathrm{~cm}^{2}$ trap) in each collection site.

$(55.1 \%$; 95\% CI $=40.3-69.1 \%)$ were positive for phlebotomine sandflies, of which 15/24 (62.5\%; $95 \% \mathrm{CI}=40.8-80.4 \%)$ were on the coastal side, and $12 / 25(48.0 \%$; $95 \% \mathrm{CI}=28.3-68.2 \%)$ were on the Apennine side, with no significant difference between the two areas (Pearson chi-square $=1.0$; $P=0.308)$. Of the 27 positive sites, $21(77.8 \% ; 95 \%$
$\mathrm{CI}=57.3-90.6 \%)$ resulted positive for $P$. perniciosus, $13 / 24(54.2 \%$; $95 \% \mathrm{CI}=33.2-73.8 \%)$ along the coastal side, and $8 / 25(32.0 \%$; $95 \% \mathrm{CI}=15.7-53.5 \%)$ along the Apennine side, with no significant difference between the two Vesuvius sides (Pearson chisquare $=2.5 ; P=0.117)$. The cumulative density (number of specimens $/ \mathrm{m}^{2}$ of sticky trap/two nights) of P. perniciosus was 3.9. However, it was found to be significantly more abundant on the coastal side (5.8) as compared to the Apennine side (1.4) $(P=0.043)$. A map showing the relative density of P. perniciosus in each collection site is shown in Fig. 3.

Data on elevation, slope and aspect of the sites monitored are reported in Table 2 . No significant differences were observed between the two sides of Mt. Vesuvius area as regards elevation (low) and slope (low). However, significant differences were evidenced for the aspect, namely south-west for the coastal side and north-east for the Apennine side. Data regarding land use of the sites are reported in Table 3. Significant differences were observed between the two sides regarding land use; in the

Table 2. Median values of elevation, slope and aspect for the 49 sandfly collection sites on the coastal and Apennine sides of Mt. Vesuvius.

\begin{tabular}{|c|c|c|c|c|c|c|c|c|c|c|}
\hline \multirow{2}{*}{$\begin{array}{l}\text { Mt. } \\
\text { Vesuvius } \\
\text { side }\end{array}$} & \multirow[t]{2}{*}{$\begin{array}{c}\text { No. of sites } \\
\text { examined }\end{array}$} & \multicolumn{3}{|c|}{$\begin{array}{c}\text { Elevation } \\
(\mathrm{m} \text { above sea level) }\end{array}$} & \multicolumn{3}{|c|}{ Slope $\left({ }^{\circ}\right)$} & \multicolumn{3}{|c|}{ Aspect $\left({ }^{\circ}\right)$} \\
\hline & & Median & Min-Max & $\mathrm{P}^{\mathrm{a}}$ & Median & Min-Max & $\mathrm{P}^{\mathrm{a}}$ & Median & Min-Max & $\mathrm{P}^{\mathrm{a}}$ \\
\hline Coastal & 24 & 211.0 & $10-850$ & & 6.0 & $0-21$ & & 269.0 & $89-357$ & \\
\hline Apennine & 25 & 210.0 & $98-456$ & 0.697 & 5.0 & $1-25$ & 0.416 & 86.0 & $1-358$ & 0.006 \\
\hline
\end{tabular}

a Mann-Whitney U test

Table 3. Distribution of 49 phlebotomine collection sites according to land use classes (level 1) in the Mt. Vesuvius area.

\begin{tabular}{|c|c|c|c|c|c|c|c|}
\hline \multirow[t]{2}{*}{ Land use } & \multicolumn{3}{|c|}{ Coastal side $($ no. of sites $=24$ ) } & \multicolumn{3}{|c|}{ Apennine side (no. of sites $=25$ ) } & \multirow[b]{2}{*}{$\mathrm{P}^{\mathrm{a}}$} \\
\hline & Frequencies & $\%$ & $95 \% \mathrm{CI}$ & Frequencies & $\%$ & $95 \% \mathrm{CI}$ & \\
\hline $\begin{array}{l}\text { Forest and } \\
\text { semi-natural areas }\end{array}$ & 6 & 25.0 & $10.6-47.0$ & 1 & 4.0 & $0.2-22.3$ & \\
\hline $\begin{array}{l}\text { Agricultural } \\
\text { areas }\end{array}$ & 11 & 45.8 & $26.2-66.7$ & 6 & 24.0 & $10.2-45.5$ & \\
\hline $\begin{array}{l}\text { Artificial } \\
\text { surfaces }\end{array}$ & 7 & 29.2 & $13.4-51.2$ & 18 & 72.0 & $50.4-87.1$ & 0.007 \\
\hline
\end{tabular}

\footnotetext{
aFisher's exact test
} 
coastal side, collection sites were characterized by the predominance of green environments (forest, semi-natural and agricultural areas), whereas artificial surfaces (namely urban environment) were more frequent in the collection sites located along the Apennine side.

\section{Discussion}

The Mt. Vesuvius area is an old and stable focus of intense zoonotic VL transmission, with some 40 human cases recorded annually and CanL seroprevalences in the range of 23.3-31.1\% (Gramiccia et al., 1992; Gradoni et al., 1993; Maroli et al., 2001; Cringoli et al., 2002; Baldi et al., 2004; di Martino et al., 2004; Rinaldi et al., 2005). The sandfly P. perniciosus has been recorded as the sole vector (Maroli et al., 1994a; Ascione et al., 1996). This species is known to be very abundant along the coastal regions of Italy at 200-300 m above sea level; the highest elevation at which this species was recorded is $1070 \mathrm{~m}$, in the Apennines of the Abruzzo region (Maroli et al., 1991). Our study confirms that P. perniciosus is widespread in the Mt. Vesuvius area and that it can be regarded as the only vector of leishmaniasis in the area. The other phlebotomine species collected during the study have no role in L. infantum transmission (Killick-Kendrick, 1990).

In the present entomological survey, GIS was used in order to map the distribution of $P$. perniciosus along the coastal and the Apennine sides of the Mt. Vesuvius; and to relate its distribution to environmental features, namely elevation, aspect, slope and land use. Our findings show that $P$. perniciosus is widespread in both the coastal and Appenine sides of Mt. Vesuvius although higher densities were found on the coastal side than on the Apennine side.

The only environmental differences found between the two sides, of the factors examined, were aspect and land use. The coastal side is characterized by the predominance of green vegetated environments (forest, semi-natural and agricultural areas), whereas urban environments are found more frequently in the Apennine side. These differences could be responsible for the differences in P. perniciosus densities between the two sides. However, even low densities of this competent vector, especially when associated with an urban environment, seem sufficient to ensure Leishmania transmission among susceptible hosts. In fact, no significant differences were found in the incidence of human cases recorded for the two sides of Mt. Vesuvius in studies done over a $1996-2005$ period $(2.8 / 10,000$ in the coastal versus 1.8/10,000 in the Apennine side; data on file, Istituto Superiore di Sanità, Rome) nor in canine leishmaniasis seroprevalence of the two areas (unpublished data).

GIS and RS are useful tools for epidemiologists and other scientists working in the geospatial health field to provide much needed data regarding the spatial and climatic parameters which determine the distribution limits of communicable (parasitic) diseases at various scales, for example, at the district, country or regional levels (Bergquist, 2006). Regarding leishmaniasis, GIS/RS has been mostly employed to produce predictive models that, although identifying geographic areas generally permissive for disease transmission does not specifically identify areas where disease transmission actually occurs, owing to the focal nature of the phlebotomine vectors, which require niches where both blood-feeding sources and microclimate are conducive for resting, breeding and survival (GebreMichael et al., 2004).

Studies reported here using high spatial resolution GIS data layers on $P$. perniciosus distribution and associated environmental features on the coastal and Appenine sides of Mt. Vesuvius successfully revealed major differences in density of this phlebotomine vector associated with aspect and land use.

Vector density differences were not reflected in records of $L$. infantum transmission to humans or dogs in 1999-2005 in the current studies; however, suggesting the need to consider other environmental, mammalian host availability, or other risk factors in further studies. Descriptive maps of vector density and environmental features developed in the 
current work based on ground observations provide essential foundation data for further studies towards the long-term aim of generating predictive maps of leishmaniasis risk by statistical patternmatching (Randolph, 2000) and ecological niche modelling methods.

\section{References}

Ascione R, Gradoni L, Maroli M, 1996. Eco-epidemiological study of Phlebotomus perniciosus in foci of visceral leishmaniasis in Campania. Parassitologia 38, 495-500.

Auger E, Gasparini P, Virieux J, Zollo A, 2001. Sismic evidence of an extended magmatic sill under Mt. Vesuvius. Science 16, 1510-1512.

Baldi L, Mizzoni V, Guarino A, 2004. Canine leishmaniasis in Campania: new and old foci. Parassitologia 46, 217-220.

Bavia ME, Carneiro DD, Gurgel Hda C, Madureira Filho C, Barbosa MG, 2005. Remote sensing and geographic information systems and risk of American visceral leishmaniasis in Bahia, Brazil. Parassitologia 47, 165-169.

Bergquist R, 2006. Preface. Geospatial Health 1, 1.

Bettini S, Gramiccia M, Gradoni L, Atzeni MC, 1986. Leishmaniasis in Sardinia. II. Natural infection of Phlebotomus perniciosus Newstead, 1911, by Leishmania infantum Nicolle, 1908 in the province of Cagliari. Trans R Soc Trop Med Hyg 80, 458-459.

Bettini S, Maroli M, Loddo S, Atzeni C, 1991. Leishmaniasis in Sardinia. VI. Further observations on the biology of Phlebotomus perniciosus Newstead, 1911, Phlebotomus perfiliewi Parrot, 1930, and Sergentomyia minuta Rondani, 1843 (Diptera: Psychodidae). Bull Soc Vector Ecol 16, 230-244.

Biocca E, Coluzzi A, Costantini R, 1977. Osservazioni sulla attuale distribuzione dei flebotomi italiani e su alcuni caratteri morfologici differenziali tra le specie del sottogenere Phlebotomus (Larroussius). Parassitologia 19, 19-31.

Bongiorno G, Habluetzel A, Khoury C, Maroli M, 2003. Host preferences of phlebotomine sandflies at a hypoendemic focus of canine leishmaniasis in central Italy. Acta Trop 88, 109-116.

Brianti E, Drigo M, Zirilli VB, Forino D, Poglayen G, Giannetto S, 2006. Proposal of health information system (HIS) as tool for the epidemiological surveillance of leishmaniasis in urban areas. Parassitologia 48, 111-113.

Corradetti A, 1962. Phlebotomus and leishmaniasis in northcentral Italy (Apennine region). Sci Rep Ist Sup Sanità 2, 103-109.

Cringoli G, Pietrobelli M, 2006. Distribution of canine leishmaniosis (CanL) in Italy: what is changing? Vet Res Commun 30, 31-34.

Cringoli G, Rinaldi L, Capuano F, Baldi L, Veneziano V,
Capelli G, 2002. Serological survey of Neospora caninum and Leishmania infantum co-infection in dogs. Vet Parasitol 106, 307-313.

Cringoli G, Rinaldi L, Veneziano V, Musella V, 2005. Disease mapping and risk assessment in veterinary parasitology: some case studies. Parassitologia 47, 9-25.

Croset H, Rioux JA, Maistre M, Bayer N, 1978. Les phlébotomes de Tunisie (Diptera, Phlebotomidae). Mise au point systématique, chronologique et éthologique. Ann Parasit Hum Comp 53, 711-749.

Cross ER, Newcomb WW, Tucker CJ, 1996. Use of weather data and remote sensing to predict the geographic and seasonal distribution of Phlebotomus papatasi in southwest Asia. Am J Trop Med Hyg 54, 530-536.

di Martino L, Gramiccia M, Occorsio P, Di Muccio T, Scalone A, Gradoni L, 2004. Infantile visceral leishmaniasis in the Campania region, Italy: experience from a paediatric referral centre. Parassitologia 46, 221-223.

Gebre-Michael T, Malone JB, Balkew M, Ali A, Berhe N, Hailu A, Herzi AA, 2004. Mapping the potential distribution of Phlebotomus martini and P. orientalis (Diptera: Psychodidae), vectors of kala-azar in East Africa by use of geographic information systems. Acta Trop 90, 73-86.

Gradoni L, Pizzuti R, di Martino L, Gramiccia M, Pempinello R, Gaeta GB, Ferrara M, Scotti S, Altieri S, 1993. The epidemiology and surveillance of visceral leishmaniasis in the Campania region of Italy. The value of zymodeme typing. Epidemiol Infect, 111, 297-306.

Gradoni L, Pizzuti R, Scalone A, Russo M, Gramiccia M, di Martino L, Pempinello R, Gaeta GB, 1996. Recrudescence of visceral leishmaniasis unrelated to HIV infection in the Campania region of Italy. Trans R Soc Trop Med Hyg 90, 234-235.

Gramiccia M, Gradoni L, di Martino L, Romano R, Ercolini D, 1992. Two syntopic zymodemes of Leishmania infantum cause human and canine visceral leishmaniasis in the Naples area, Italy. Acta Trop 50, 357-359.

Killick-Kendrick R., 1990. Phlebotomine vectors of the leishmaniases: a review. Med Vet Entomol 4, 1-24.

Léger N, Pesson B, Madulo-Leblond G, Abonnenc E, 1983. Sur la differérenciation des femelles du sous-genre Larroussius Nitzulescu, 1931 (Diptera-Phlebotomidae) de la région méditerranéenne. Ann Parasitol Hum Comp 58, 611-623.

Maroli M, Bettini S, 1977. Leishmaniasis in Tuscany (Italy). I. An investigation on phlebotomine sandflies in Grosseto province. Trans R Soc Trop Med Hyg 71, 315-321.

Maroli M, Bigliocchi F, Khoury C, 1994b. Sandflies in Italy: observations on their distribution and methods for control. Parassitologia 36, 251-264.

Maroli M, Cavallini C, Khoury C, Miceli M, Manilla G, 1991. Indagine entomologica sui flebotomi (Diptera, Psycodidae) in provincia di L'Aquila (Abruzzo). Parassitologia 33, 127-131.

Maroli M, Gramiccia M, Gradoni L, Ready P, Smith DF, Equino C, 1988. Natural infections of phlebotomine sand- 
flies with Trypanosomatidae in central and south Italy. Trans R Soc Trop Med Hyg 82, 227-228.

Maroli M, Gramiccia M, Gradoni L, Troiani M, Ascione R, 1994a. Natural infection of Phlebotomus perniciosus with an enzymatic variant of Leishmania infantum in the Campania region of Italy. Acta Trop 57, 333-335.

Maroli M, Khoury C, 1998. Leishmaniasis vectors in Italy. In: Proceedings of New Trends in Epidemiology and Control of Leishmaniasis in the Mediterranean area. Palermo, Italy. G Ital Med Trop 3, 69-75.

Maroli M, Mizzoni V, Siragusa C, D’Orazi A, Gradoni L, 2001. Evidence for an impact on the incidence of canine leishmaniasis by the mass use of deltamethrin-impregnated dog collars in southern Italy. Med Vet Entomol 15, 358-363.

Nieto P, Malone JB, Bavia ME, 2006. Ecological niche modeling for visceral leishmaniasis in the state of Bahia, Brazil, using genetic algorithm for rule-set prediction and growing degree day-water budget analysis. Geospatial Health 1, 115-126.

Randolph SE, 2000. Ticks and tick-borne disease systems in space and from space. Adv Parasitol 47, 217-243.

Rinaldi L, Veneziano V, Baldi L, Mizzoni V, Musella V,
Santaniello M, Cringoli G, 2005. Serological survey of Leishmania infantum and Neospora caninum co-infection in dogs. Proceedings of the III World Congress on Leishmaniosis, $197 \mathrm{p}$.

Rinaldi L, Musella V, Biggeri A, Cringoli G, 2006. New insights into the application of geographical information systems and remote sensing in veterinary parasitology. Geospatial Health 1, 33-47.

Rioux JA, Golvan YJ, Croset H, Houin R, Juminer B, Bain O, Tour S, 1967. Ecologie des leishmanioses dans le Sud de la France.1. Les phlébotomes. Echantillonage-ethologie. Ann Parasit Hum Comp 42, 561-603.

Theodor O, 1958. Psychodidae-Phlebotominae. In: Die Fliegen der Palaearktischen Region, 9c, Lindner, E. (editor). Stuttgart: E. Schweizerbart'sche Verlagsbuchhandlung, pp 1-55.

Thomson MC, Elnaiem DA, Ashford RW, Connor SJ, 1999. Towards a kala-azar risk map for Sudan: mapping the potential distribution of Phlebotomus orientalis using digital data of environmental variables. Trop Med Int Health 4, 105-113.

Trotz-Williams LA, Trees AJ, 2003. Systematic review of the distribution of the major vector-borne parasitic infections in dogs and cats in Europe. Vet Rec 152, 97-105. 